\title{
Non-Biofouling Property of Well-defined Concentrated Polymer Brushes
}

Chiaki Yoshikawa, ${ }^{\mathrm{a}} *$ Jun Qiu, ${ }^{\mathrm{b}}$ Chih-Feng Huang, ${ }^{\mathrm{a}, \mathrm{c}}$ Yoshihisa Shimizu, ${ }^{\mathrm{a}}$ Junji Suzuki, ${ }^{\mathrm{a}}$ Edith van $\operatorname{den} \operatorname{Bosch}^{\text {d* }}$

${ }^{a}$ WPI Research Center for Materials Nanoarchitectonics, National Institute for Materials Science (NIMS), Tsukuba, Ibaraki 305-0044, Japan

${ }^{\mathrm{b}}$ DSM Ahead/TS, 6167 RD Geleen, The Netherlands

${ }^{c}$ Department of Chemical Engineering, National Chung Hsing University, Taichung 40227, Taiwan ${ }^{\mathrm{d} D S M}$ Biomedical, 6167 RD Geleen, The Netherlands

Corresponding authors: YOSHIKAWA.Chiaki@nims.go.jp and edith.bosch-van-den@dsm.com

(C) 2015. This manuscript version is made available under the Elsevier user license http://www.elsevier.com/open-access/userlicense/1.0/ 


\begin{abstract}
The non-biofouling properties of polymer brushes of poly(2-hydroxyethyl methacrylate) (PHEMA), poly(2-hydroxyethyl acrylate) (PHEA), and poly(poly(ethylene glycol) methyl ether methacrylate) (PPEGMA) were comprehensively studied by varying graft densities (i.e., semi-dilute and concentrated regimes) and the thicknesses at the dry state of 2 and $10 \mathrm{~nm}$. Semi-dilute polymer brushes (SDPBs) were prepared by grafting-to method and concentrated polymer brushes (CPBs) were prepared by surface-initiated atom transfer radical polymerization (SI-ATRP). The adsorptions of proteins with different sizes were investigated on the brushes by quartz crystal microbalance (QCM) from a view point of size-exclusion effect specific to the CPBs. We confirmed that due to the size exclusion effect, the CPBs of all the three much suppressed proteins adsorption and human umbilical vein endothelial cell (HUVEC) adhesion compared with the corresponding SDPBs. In order to investigate what type of proteins adsorbed on the brushes to trigger cell adhesion, we identified adsorbed proteins from fetal bovine serum on the brushes using a high-performance liquid chromatography coupled with tandem mass spectrometry (LC-MS/MS). Proteins were only detected on the SDPBs. Interestingly, the number and type of identified proteins were different on the SDPBs, indicating that chemical composition of the SDPBs affects protein adsorption, hence the cell adhesion. The adsorption mechanism on the SDPBs could be due to the combination of protein-polymer interaction and physical inclusion, whereas CPBs exhibit size exclusion effect combined with neutral hydrophilic nature of polymer, thereby, that provides excellent non-biofouling property.
\end{abstract}

\title{
Keywords
}

concentrated polymer brush / living radical polymerization / protein / cell / non-biofouling 


\section{Introduction}

The surface of a biomaterial plays a crucial role in its performance because the biomaterial is often used in direct contact with biological tissue, blood, or other body liquids. When a surface contacts with living matter, irreversible protein adsorption is first to occur. Next it triggers cell adhesion, consequently causing other cell responses such as cell spreading, migration, proliferation, and so on. Such bio-fouling starting from protein adsorption and cell adhesion often leads to undesired results, e.g., inflammation, immunological rejection and hampering of selective detection in biosensors. Therefore, it is essential for a material surface to perfectly prevent the biofouling. Toward the requirements, polymer grafting has been extensively studied to investigate protein adsorption as a function of grafting density [1]. It is generally thought that if protein adsorption, the first biological reaction, could be perfectly prevented on the surface then consequent cell reactions would never occur.

Recently, living radical polymerization (LRP) has been successfully applied to graft polymerization to achieve extraordinarily highly dense polymer brushes of well-defined low-polydispersity polymers on various inorganic/organic materials [2-4]. The obtained high density polymer brush, so-called "concentrated" polymer brush (CPB) shows unique structure and properties quite different from those of the semi-dilute brush (SDPB) prepared by conventional methods. For example, in a good solvent, the polymer chains in the CPB are highly extended, nearly to their full length $[3,5,6]$. Reflecting the high-extension structure, the swollen CPB exhibits unprecedented properties such as strong repulsion against compression [3, 6], super lubrication $[3,7,8]$ and size-exclusion effects [9]. Notably, the structure and properties of the swollen CPB are understood by a consummate balance between a large osmotic pressure in a solvent (mixing entropy) and an entropically unfavorable conformation of the highly extended chains (conformational entropy). Toward such entropically driven features of the solvent-swollen CPB, we 
recently successfully demonstrated that a concentrated poly(2-hydroxyethyl methacrylate) (PHEMA) brush showed excellent protein repellency as compared with the corresponding cast film and SDPBs because of its high compaction to obtain unique size-exclusion effect (Scheme S1); when protein sizes are sufficiently larger than the average distance between nearest-neighboring graft points, $d$ (= (graft density $\left.)^{-1 / 2} \mathrm{~nm}\right)$, are excluded from the brush layer to avoid the large (mainly conformational) entropy loss caused on the highly extended chains by the entrance of the large molecules, and their adsorption can be suppressed [10,11]. Although the SDPBs also have a size-exclusion effect, this effect is minor for them because the degree of the chain extension is much less significant in these brushes, and thus even a larger protein than $d$ will partly diffuse into the brush layer depending on its size. Due to the excellent protein repellency, the concentrated PHEMA brush almost prevented the adhesion of evaluated cell line (HUVEC) [12]. We also confirmed that CPBs of neutral hydrophilic polymers, PHEMA, poly(2-hydroxyethyl acrylate) (PHEA) and poly(poly(ethylene glycol) methyl ether methacrylate) (PPEGMA) suppressed L929 fibroblast cell adhesion to almost undetectable level [13]. This result strongly indicates that proteins little adsorbed on the CPBs because the size-exclusion effect should be equally endowed with all the swollen CPBs as same as the concentrated PHEMA brushes, however, there is no experimental evidence to confirm this notion.

In this work, from the view point of the size-exclusion effect, we comprehensively evaluated protein adsorption and cell adhesion on neutral hydrophilic polymer brushes by varying graft densities (in SDPB and CPB regimes) and thicknesses (ca. 2 and $10 \mathrm{~nm}$ ). Herein, we used PHEMA, PHEA and PPEGMA as model polymers. First, in order to substantiate the size-exclusion effect of all the three CPBs, we investigated irreversible protein adsorptions on the brushes as a function of graft density and protein sizes using a quartz crystal microbalance (QCM). Then we examined fetal bovine serum (FBS) adsorption and HUVEC adhesions on the brushes. FBS is generally used for cell culture and the adsorptions of FBS-proteins play an important role in cell adhesion. Thus, in 
addition, we attempted to identify adsorbed proteins from FBS on the brushes by liquid chromatography tandem mass spectroscopy (LC-MS/MS).

Although surface-initiated LRP has been applied for creating biointerfaces in elsewhere, so far the strategy to utilize the unique structure and properties of CPB for this purpose has been little discussed clearly. This work will provide useful information to develop a non-biofouling surface using CPBs.

\section{Material and Methods}

\subsection{Materials}

2-Hydroxyethyl methacrylate (HEMA) (99\%, Wako Pure Chemical, Japan) and 2-hydroxyethyl acrylate (HEA) (99\%, Wako Pure Chemical, Japan) were distilled under vacuum. Poly(ethylene glycol) methyl ether methacrylate (average $M_{\mathrm{n}}$ 475) (PEGMA) (Aldrich) was purified by passing through neutral alumina. $\mathrm{Cu}(\mathrm{I}) \mathrm{Br}(99.9 \%$, Wako), ethyl 2-bromoisobutylate (EBIB) (99\%, Wako), 2, 2'-bipyridine (bpy) (99\%, Nacalai Tesque, Japan), methanol (99\%, Nacalai), and ammonia $\left(\mathrm{NH}_{3}\right)$ $(28 \%$ aq, Nacalai) were used as received. $\{[(2-B r o m o-2-m e t h y l p r o p i o n y l) o x y] p r o p y l\}$ triethoxysilane (BPE) was synthesized according to literature [10]. Silica particles (SiPs) with a mean diameter of $130 \mathrm{~nm}$ (SEWHOSTERKE-E10, 20 wt\% suspension of SiPs in ethylene glycol) were purchased from Nippon Shokubai Co., Ltd., Osaka Japan. Bradykinin (BR), insulin (Ins), bovine serum albumin (BSA), immunoglobulin (IgG), and fibronectin $(\mathrm{FN})$ were purchased from Sigma-Aldrich and used as received.

\subsection{Preparation of concentrated polymer brushes $(C P B s)$.}

CPBs of PHEMA, PHEA, and PPEGMA were prepared on a silicon wafer and a $\mathrm{SiO}_{2}$-deposited QCM chip by surface-initiated atom transfer radical polymerization (SI-ATRP) as reported previously [10-13]. As an example, a typical run of SI-ATRP of HEMA is detailed as 
follows: Firstly, BPE, a fixed initiator for ATRP, was immobilized on the surfaces of the substrates; the substrates were immersed in an ethanol solution of BPE (1 wt $\%)$ and $20 \mathrm{w} / \mathrm{v} \%$ aqueous $\mathrm{NH}_{3}$ (7wt $\%)$ for $18 \mathrm{~h}$ at room temperature and were washed with ethanol. Then, concentrated PHEMA brush with a dry thickness $(L)$ of $10 \mathrm{~nm}$ was prepared as follows; a methanol solution of HEMA (4.5 M), $\mathrm{Cu}(\mathrm{I}) \mathrm{Br}(25 \mathrm{mM})$, bpy $(63 \mathrm{mM})$, and a free initiator EBIB $(22.5 \mathrm{mM})$ was prepared in a glove box purged with argon, and all chemicals were deoxygenated with argon before use in the glove box. The BPE-immobilized substrate (silicon wafer or QCM chip) and the polymerization solution were put into a glass tube with a stopcock and heated at $30{ }^{\circ} \mathrm{C}$ for a prescribed time. After the polymerization, the solution was diluted with a $N, N$-dimethylformamide (DMF) solution of $\mathrm{LiCl}$ $(10 \mathrm{mM})$ to a known concentration and analyzed by gel permeation chromatography (GPC). The conversion was determined from the GPC peak area. The substrate was thoroughly washed with methanol to remove physisorbed free polymer and impurities.

CPBs of PHEMA, PHEA, and PPEGMA were also prepared on SiPs by SI-ATRP as well as on the flat substrates. As an example, a typical run using PHEMA is detailed: a MeOH solution of HEMA (4.5 M), Cu(I)Br (25 mM), bpy (63 mM), EBIB $(22.5 \mathrm{mM})$, and a suspension of BPE-coated SiPs $(20 \mathrm{mg})$ were prepared in the glove box and it was put into a glass tube with a stopcock. The solution was mixed at $30{ }^{\circ} \mathrm{C}$ for a prescribed time. After the polymerization, the conversion was estimated by nuclear magnetic resonance (NMR) measurement and $M_{\mathrm{n}}$ and PDI were determined by the GPC. The reaction mixture was diluted by methanol and centrifuged to collect polymer-grafted SiPs. The cycle of redispersion in methanol and centrifugation was repeated five times to remove physisorbed free polymer.

\subsection{Preparation of semi-dilute polymer brushes (SDPBs).}

SDPBs of PHEMA, PHEA and PPEGMA were prepared on the substrates by grafting-to method as previously reported [10-13]. As an example, a typical run using PHEMA was carried out as 
follows: The end-functionalized PHEMA was synthesized by ATRP with BPE (with a triethoxysilyl group) used as a free initiator. Namely, a degassed methanol solution of HEMA (4.5 M), BPE (22.5 $\mathrm{mM}), \mathrm{Cu}(\mathrm{I}) \mathrm{Br}(25 \mathrm{mM})$, and bpy $(63 \mathrm{mM})$ was heated at $30{ }^{\circ} \mathrm{C}$ for $40 \mathrm{~min}$. After reprecipitation into cooled hexane, a PHEMA $\left(M_{\mathrm{n}}=1.97 \times 10^{4}\right.$ and $\left.M_{\mathrm{w}} / M_{\mathrm{n}}=1.2\right)$ having a triethoxysilyl group at one chain end was isolated (the obtained amount was ca $1.0 \mathrm{~g}$ ).

A silicon wafer and a $\mathrm{SiO}_{2}$-deposited QCM chip were immersed in a methanol solution of the end-functionalized PHEMA (1 wt $\%)$ and $\mathrm{NH}_{3}(2 \mathrm{wt} \%)$ for $18 \mathrm{~h}$ at room temperature and rinsed with methanol.

\subsection{QCM Measurement.}

Irreversible protein adsorptions were measured at $25{ }^{\circ} \mathrm{C}$ by a quartz crystal microbalance (QCM-D, Q-sense D300). QCM sensors with a gold electrode were washed with a piranha solution (28 w/vt\% $\mathrm{NH}_{3} / 30-35.5 \mathrm{w} / \mathrm{vol} \% \mathrm{H}_{2} \mathrm{O}_{2}=70 / 30 \mathrm{vol} / \mathrm{vol} \%$ ) and rinsed with milliQ water. On the cleaned sensor, $\mathrm{Cr}$ and $\mathrm{SiO} 2$ were sputtered with a thickness of 5 and $20 \mathrm{~nm}$, respectively. The QCM sensor with/without polymer brush was placed in a flow cell and the cell was filled with a phosphate buffer saline (PBS). PBS was injected several times until the baseline became stable. Then, a protein solution of $1.0 \mathrm{mg} / \mathrm{ml}$ was injected into the cell and kept it at $25^{\circ} \mathrm{C}$ for 1 hour. The amount of adsorbed protein $\left(\Gamma / \mathrm{ng} \mathrm{cm}^{-2}\right)$ is represented by Eq. 1 ,

$\Gamma=-\mathrm{C} \Delta \mathrm{f} / \mathrm{n}$

where $\mathrm{C}$ is the mass sensitivity constant $\left(17.7 \mathrm{ng} \mathrm{cm}^{-2} \mathrm{~Hz}^{-1}\right.$ for a $5 \mathrm{MHz}$ crystal), $\Delta \mathrm{f}_{\mathrm{n}}$ is the frequency change $(\mathrm{Hz})$ and $\mathrm{n}$ is the overtune number $(1,3,5$, and 7). The QCM test was duplicated for the brush samples.

\subsection{HUVEC adhesion test.}


HUVECs (LONZA, Switzerland) were cultured in endothelial basal medium 2 (LONZA) supplemented with EGM-2 SingleQuots (LONZA) (2\% FBS) at $37{ }^{\circ} \mathrm{C}$ in a humidified atmosphere of air containing $5 \% \mathrm{CO}_{2}$. At subconfluence, the cells were removed from the tissue culture plate polystyrene (TCPS) by trypsin treatment. HUVECs were seeded on samples $\left(1.0 \times 10^{4}\right.$ cells $/ \mathrm{cm}^{2}$ on 1- and 4-day samples and 2500 cells/ $\mathrm{cm}^{2}$ on 7-day samples) and cultured for the prescribed time. After the medium was aspirated, the substrate was gently rinsed three times with fresh PBS. The fixed cells on the samples were stained with F-actin visualization Biochem Kit (Cytoskeleton, USA) and mounted with Prolong Gold antifade reagent with DAPI (Invitorogen, USA), coloring the nuclei blue and the actin filaments red, respectively. Then the adhered cells were observed by a fluorescence microscope. Three experiments were run for each surface, and at least seven spots on a substrate were measured to obtain the mean values.

\subsection{FBS protein adsorption on polymer-grafted SiPs.}

Polymer grafted SiPs (500 mg in $2.5 \mathrm{ml}$ PBS, a total surface area of ca $1.15 \times 10^{5} \mathrm{~cm}^{2}$ ) were soaked in FBS $(22.5 \mathrm{ml})$ at $37{ }^{\circ} \mathrm{C}$ for $12 \mathrm{~h}$. After washing the SiPs 5 times with PBS to remove unadsorbed proteins, the adsorbed proteins were recovered from the SiPs by washing with $5 \mathrm{wt} \%$ sodium dodecyl sulfate (SDS) in $25 \mathrm{ml}$ PBS. The SiPs were collected by a centrifuge and discarded. Then, the SDS was removed from the supernatant by dialysis, and the protein solutions were freeze-dried (almost nothing was left in all the CPB cases). The proteins were stocked at $4{ }^{\circ} \mathrm{C}$ until they were subjected to the SDS polyacrylamide gel electrophoresis (SDS-PAGE) and LC-MS/MS analysis.

\subsection{SDS-PAGE}

In a typical run, $50 \mu \mathrm{g}$ of proteins were dissolved in $6.5 \mu 1$ of PBS and then the sample solutions for the electrophoresis were prepared according to the manufacturer provided protocol 
(NuPAGE®Bis-Tris Mini Gels, LifeTechnologies ${ }^{\mathrm{TM}}$ ). The protein bands were visualized by silver staining. The stained gel images were obtained by a scanner (CanonScan8800F, Canon, Japan).

\subsection{LC-MS/MS analysis}

The proteins were digested by trypsin to subject to a LC-MS/MS analysis (AMR Inc., Zaplous LC/MS system). Mass data was obtained with the appropriate and nucleic acid sequence data base. The MASCOT (Matrix Science, UK) search engine provided the relevant scores of each protein identified and the International Protein Index (IPI) of each protein. The known contaminants such as keratin were excluded.

\subsection{Other Measurements.}

GPC analysis of PHEMA and PPEGMA was made on a Shodex GPC 101-series high-speed liquid chromatograph (Tokyo) equipped with two Shodex gel columns, LF804 $(300 \times 80 \mathrm{~mm}$; bead size $=$ $6 \mu \mathrm{m}$; pore size $=20-3000 \AA)($ Tokyo $) . \mathrm{DMF}$ with $10 \mathrm{mM} \mathrm{LiCl}$ was used as eluent at a flow rate of $0.8 \mathrm{~mL} / \mathrm{min}\left(40{ }^{\circ} \mathrm{C}\right)$. The column system was calibrated with Tosoh standard polyethyleneglycols (PEGs) and Shodex standard poly(methyl methacyrate) (PMMAs). Sample detection and quantification were made with a Tosoh differential refractometer (RI-8020).

GPC analysis of PHEA was made on a Shodex GPC 101-serieshigh-speed liquid chromatograph (Tokyo). The equipped with two Shodex gel columns, SB-804HQ $(300 \times 80 \mathrm{~mm}$; bead size $=10 \mu \mathrm{m}$;

pore size $=\sim 2000 \AA$ ) (Tokyo). Water/acetonitrile $=3 / 2$ vol/vol \% with $10 \mathrm{mM} \mathrm{LiBr}$ was used as eluent for PHEA.

The thicknesses of the grafted polymer layers were determined by a compensator-rotating, spectroscopic ellipsometer (FiveLabCo,Ltd., Kanagawa, Japan) equipped with a HeNe laser. The polarizer angle was $45^{\circ}$, and the incident angle was $70^{\circ}$. The measurement was made on at least 3 
spots for each sample and then averaged. The graft density $(\sigma)$ was estimated from the following equation:

$$
\sigma=L \rho N_{\mathrm{A}} / M_{\mathrm{n}, \text { conv }}
$$

where $L$ is the thickness of the graft layer, $\rho$ is the bulk density of polymer $\left(\mathrm{g} / \mathrm{cm}^{3}\right), N_{\mathrm{A}}$ is the Avogadro's number, and $M_{\mathrm{n} \text {,conv }}$ is the theoretical number-average molecular weight estimated from the conversion and the molar ratio of free initiator to monomer.

Contact angles $(\theta)$ were measured in miliQ water with air bubble at room temperature using a contact angle meter CA-X (Kyowa Interface Science, Saitama, Japan). The measurements were made on at least five spots for each sample, and these $\theta$ values were averaged.

\section{Results and discussions}

\subsection{Preparation of polymer brushes}

CPBs of PHEMA, PHEA, and PPEGMA were prepared on the substrates (silicon wafers and $\mathrm{SiO}_{2}$-spputtered QCM sensors) by SI-ATRP as we previously reported [12,13]. Table 1 shows $M_{\mathrm{n}}$ and $M_{\mathrm{w}} / M_{\mathrm{n}}$ for free polymers simultaneously grown from the free initiator in the polymerization solution. These values are known as good indices for those of graft polymers [3]. The $M_{\mathrm{w}} / M_{\mathrm{n}}$ was 1.1-1.3 in all cases, suggesting that the brush samples have relatively narrow distribution in chain length. $M_{\mathrm{n}, \mathrm{c}}$, the theoretical $M_{\mathrm{n}}$ was calculated with conversion (see the footnote). Previously, we determined the absolute values of all the three polymers by GPCs with a multi-angle laser scattering detector and confirmed that they were in good agreement with the theoretical values $\left(M_{\mathrm{n}, \mathrm{s}} \mathrm{s}\right)[12,13]$. Since we applied the same polymerization conditions, $M_{\mathrm{n}, \mathrm{c}}$ was used as the absolute values to estimate the graft density $(\sigma)$. We abbreviated $\mathrm{CPB}$ with shorter chain as $\mathrm{CPB}(\mathrm{S})$ and one with longer as $\mathrm{CPB}(\mathrm{L})$.

SDPBs of PHEMA, PHEA, and PPEGMA were prepared by grafting-to method. The 
end-functionalized polymer with an alkoxysilyl group was synthesized by ATRP using BPE as a free initiator, after which it was immobilized on the substrates.

In order to categorize polymer brushes composing different kinds of polymers (with different size of monomers), the dimensionless graft density $\sigma^{*}$ (see the caption in Table 1 ) was estimated. Based on the criterion that the crossover density between SDPB and CPB is around 0.1 in $\sigma^{*}\left(\sigma_{\mathrm{c}}^{*}\right)[3,15]$, we classified the brushes into $\mathrm{CPB}$ or SDPB by $\sigma^{*}$.

The contact angle $\theta$ was measured in water at $25{ }^{\circ} \mathrm{C}$ by the air-bubble method for these brushes listed in Table 1 . The $\theta$ values for each polymer were almost the same independent of $\sigma^{*}$ and $L$, suggesting that the substrate was fully covered with the polymer segments. The $\theta$ for PPEGMA-CPB $(\mathrm{L})$ was slightly smaller than those of other PPEGMA brushes (about $5^{\circ}$ ). Although the reason for this is unclear, experimental error is probably a major factor $\left(\theta \pm 2^{\circ}\right)$.

\subsection{Adsorption of proteins with different sizes: Size-exclusion effect.}

Until now, the protein repellency was demonstrated only on the CPB of PHEMA $[10,11]$, but this should be the case with other CPB samples because this property comes from the entropically driven size-exclusion effect unique to the swollen CPB. Thus, in order to verify the size-exclusion effect on other hydrophilic polymers, we examined protein adsorption on the polymer brushes of PHEMA, PHEA, and PPEGMA by QCM.

The interactions between protein and polymer brush coated sample are simply modeled by three cases [1]: (a) protein diffuses into the brush layer and adsorb on the substrate surface, (b) protein adsorb on the outermost surface of the swollen brush layer, and (c) protein diffuses into the brush layer and adsorb on the segment. As shown in scheme S1a, the graft chains in a swollen CPB are highly extended and hence highly oriented. Therefore, the distance between the neighboring graft chains, $D$ would be almost same as $d\left(=\sigma^{-1 / 2}\right)$ in the entire brush layer, from the 
substrate surface to the outermost surface throughout. This structural feature of the swollen CPB would bring about its unique size-exclusion effect. Since $d$ can be a rough threshold for the size-exclusion, proteins sufficiently larger than $d$ would be excluded from the brush layer. Then, if proteins do not have affinity interaction with the outermost surface of the $\mathrm{CPB}$, their adsorption should be suppressed.

QCM experiments were conducted on the brush samples with different graft densities (in SDPB and $\mathrm{CPB}$ regimes) and dry thicknesses $(2$ and $10 \mathrm{~nm}$ ) for a series of proteins with different sizes. The characteristics of the five proteins are listed in Table 2. The crystallographic data is not available for BR. The apparent molecular weights of these proteins $\left(M_{\text {pul }}\right)$ were estimated by pullulan-calibrated GPC as we previously reported $[10,11]$. Their radii of gyration $\left(R_{\mathrm{g}}\right)$ were calculated with the known relation between the $R_{\mathrm{g}}$ and molecular weight of pullulan $[16,17]$. Since the values of $2 R_{\mathrm{g}}$ were similar to the protein sizes of the crystallographic dimensions [18-25], they can be used as a gauge for dimensional comparison. After 1h soaking, the surfaces were washed several times with fresh PBS to remove unbound or weakly bound proteins. With the base line difference in frequency before and after the protein adsorption, we estimated the amount of irreversible protein adsorption on the brush samples. Figure 1 shows the amount of irreversible protein adsorption on the brushes listed in table 1 and the $\mathrm{SiO}_{2}$ sputtered sensor $\left(\mathrm{SiO}_{2}\right)$ as reference. The amounts were normalized with the value on the $\mathrm{SiO}_{2}$ (see table 2).

The PHEMA-CPB(L) showed little adsorption for all the five proteins. This was obviously due to the size-exclusion effect of the CPB. FN, IgG, BSA and Ins, which were larger than $d$, were size-excluded from the brush layer and their adsorptions would be suppressed. The PHEMA-CPB $(\mathrm{S})$ slightly adsorbed FN although the size of FN $\left(=2 R_{\mathrm{g}}\right)$ is larger than $d$. Although this reason is unclear, the swollen thickness of PHEMA-CPB $(\mathrm{S})$ might be too short to suppress affinity interaction between FN and substrate. In comparison of $2 R_{\mathrm{g}}$ and $d$, BR could diffuse into the brush layer, however, it did not adsorb on the PHEMA-CPBs. This was probably because BR had 
no affinity interaction with PHEMA segment. On the other hand, FN and IgG displayed a small amount of adsorption on the PHEMA-SDPB, but no adsorption was seen for BSA, Ins, and BR. The proteins were treated as spherical particles to simplify interpretation of the size-exclusion effect, but in fact, each protein has its own anisotropic shape, e.g., the ellipsoidal shape of BSA. In addition, as shown in S1b, the distance between the neighboring graft chains in the SDPB would be larger than $d$ by getting away from the substrate surface. Therefore, even though the sizes $\left(2 R_{\mathrm{g}}\right)$ of $\mathrm{FN}$ and $\operatorname{IgG}$ were sufficiently larger than $d$, the proteins can penetrate into the SDPB layer causing the irreversible protein adsorptions.

All the five proteins did not adsorb on the PHEA-CPBs. According to the correlation between $2 R_{\mathrm{g}}$ and $d$, the four larger proteins were size-excluded from the PHEA-CPBs and their adsorption was suppressed. The PHEA SDPB showed significant adsorption of BSA and BR. It is unclear why BR diffusing into the brush layers adsorbed on only the SDPB, not on the CPB. This might be caused by some factors specific to the SDPB such as chain mobility, water content, surface charge, and etc.

Due to the size-exclusion effect, the PPEGMA-CPBs prevented protein adsorptions of all the five proteins as well as the CPBs of PHEA. Although the smallest protein $(\mathrm{BR})\left(2 \mathrm{R}_{\mathrm{g}}<d\right)$ penetrated into the brush layer, it did not adsorb because of low affinity interaction with PPEGMA segment. On the other hand, BSA, Ins, and BR adsorbed on the PPEGMA-SDPB.

It should be noted that the CPBs with different thicknesses suppressed protein adsorptions. This indicates the very feature of the $\mathrm{CPB}$, namely, it has the size-exclusion effect from the substrate surface to the outer surfaces throughout. It is unclear that why proteins excluded from the CPB layers did not adsorb on the brush surfaces. The interaction between protein and outermost brush surface might be decreased by the mobility of the brush chain or the structure of water near the brush surface. Interestingly, the SDPBs of all the three polymers show disagreement in adsorbed proteins. The interaction between protein and SDPB might be affected by chemical compositions. 
We demonstrated that the size-exclusion effect, namely protein repellency, was given on the $\mathrm{CPBs}$ of all the three polymers, independent of chemical compositions and hydrophilicity. As a matter of course, in some cases, protein characters including their shapes and the affinity interactions between the proteins and the polymers may be dominant causing protein adsorptions. However, it is apparent that the size-exclusion effect of the CPBs plays an important role in preventing protein adsorption.

\subsection{HUVEC adhesion}

As described earlier, an irreversible protein adsorption typically triggers cell adhesion. Thus, the CPBs of PPEGMA, PHEMA, and PHEA brushes which showed excellent protein repellency are also expected to suppress cell adhesion. The HUVEC adhesion test was carried out on the brush samples as well as tissue culture polystyrene (TCPS) as reference. HUVECs are one of the important model cells to study cell adhesion behavior such as morphology change as well as blood-related responses such as angiogenesis [26-29]. 10000 cells $/ \mathrm{cm}^{2}$ of HUVEC were seeded on the samples, which were then incubated for 1 and 4 days. Since the cell concentration was too high to allow incubation for 7 days, the cells were seeded at lower concentration $\left(2500 \mathrm{cells} / \mathrm{cm}^{2}\right)$ for the 7-day incubation test. After the incubation, the adherent cells were fixed on the samples and stained using DAPI and rhodamine/phalloidin to show the nuclei (blue) and actin filaments (red), respectively. The fluorescent images of the adherent HUVECs are shown in supplementary information (figure S1). The colored cells were counted to obtain the mean value. Figure 2 shows the amount of adherent HUVECs on the samples for 1, 4, and 7 days. The total cell number was normalized with the initial seeded cell number. HUVECs showed significant adherence on all the corresponding SDPBs, at similar levels as on the TCPS. In contrasts, all the CPBs with the exception of the PHEMA-CPB(S), displayed suppressed HUVEC adhesion. These results can be 
explained by the protein repellency of the CPBs, which in turn reduces the ability of the HUVECs to adhere to the surface.

\subsection{Adsorption of FBS protein.}

In the aforementioned HUVEC culture, FBS was added into the medium to supply cells with nutrition and growth factors. It is generally known that cell adhesion on materials is mainly caused by the irreversible adsorption of proteins from FBS. Herein, by QCM, we also investigated the adsorption of proteins from FBS on the brushes listed in Table 2. Figure 3 shows the amount of adsorbed protein on the brush samples as well as on $\mathrm{SiO}_{2}$ surface as a reference. FBS showed low levels of adsorption onto all the $\mathrm{CPB}(\mathrm{L}) \mathrm{s}$ and the $\mathrm{CPB}(\mathrm{S}) \mathrm{s}$ of PPEGMA and PHEA. On the other hand, FBS adsorbed onto all the SDPBs and slightly onto the PHEMA-CPB(S). The reason why FN and FBS proteins adsorbed on $\operatorname{PHEMA-CPB}(\mathrm{S})$ is not unclear, however, this result was in agreement with the result on HUVEC adhesion. Then, in order to identify which proteins adsorb on the brushes, LC-MS/MS analysis was carried out. The brushes of PPEGMA, PHEMA, and PHEA were prepared on SiPs as listed in Table S1. SiPs were used as substrates possessing large surface area to recover sufficient amount of proteins for the analysis. $M_{\mathrm{n}}$ and $M_{\mathrm{w}} / M_{\mathrm{n}}$ for free polymers were almost the same as those on flat substrates as listed in Table 1. The amounts of polymers grafted on SiPs were estimated by elemental analysis. The $\sigma$ s were calculated with the graft amount, the known density, surface area and the $M_{\mathrm{n}, \mathrm{c}}$ of the free polymers. Since the graft amounts of all the SDPBs were too low to be estimated by elemental analysis, we adopted the values obtained on silicon wafers. When we graft polymer brush on the curvature substrate such as the SiP, even if the apparent graft density $\sigma$ is in the CPB regime, the effective surface density will go from CPB to SDPB regimes by increasing the graft chain length. Thus, on the basis of the criterion of CPB on a SiPs well-argued by Ohno et al [30], we carefully chose the size of $\mathrm{SiP}$ (diameter $=130 \mathrm{~nm}$, surface 
area $=2.3 \times 10^{5} \mathrm{~nm}^{2} / \mathrm{g}$ ) to maintain the CPBs structures of all the three polymers with the chain lengths $\left(M_{\mathrm{n}, \mathrm{c}}\right)$ as shown in table $\mathrm{S} 1$

The polymer grafted SiPs as well as a bare $\mathrm{SiP}$ were incubated in FBS at $37{ }^{\circ} \mathrm{C}$, and the adsorbed proteins were recovered from the samples by SDS washing. Then, for the LC-MS/MS analysis, we removed SDS from the protein solutions by dialysis. Since we could not rule out the possibility that some proteins selectively adsorbed on the dialysis membrane, thereby leading to LC-MS/MS identifying fewer proteins than the actual adsorbed proteins, the molecular weight of FBS proteins (the band patterns) was compared before/after the dialysis treatment using a SDS-PAGE. $10 \mathrm{ml}$ of FBS and SDS $(5 \mathrm{wt} / \mathrm{vol} \%)$ were mixed at $37{ }^{\circ} \mathrm{C}$ for $1 \mathrm{~h}$. Then, the mixture was put into a dialysis and kept it in milliQ water for $24 \mathrm{~h}$ to remove SDS. The solution was freeze-dried to collect dried proteins. The dried proteins were dissolved with $10 \mathrm{ml}$ of PBS to adjust the initial FBS concentration, and then they were subjected to SDS-PAGE analysis. The result is shown in supplementary content (figure S2a). The band positions were almost same in both samples. This indicates that the selective protein adsorption little occur onto the dialysis membrane. Further, in order to confirm that SDS washing removed all the proteins from the surfaces, we collected the bare-SiPs after the SDS washing and loaded the bare-SiPs solution directly on the gel for SDS-PAGE. As a reference, we also loaded the bare-SiPs without SDS washing. As shown in figure S2b, the bare-SiPs with SDS washing showed no protein bands, indicating that the washing was completed. On the other hand, the bare-SiPs showed the same protein bands as obtained by the dialysis method (figure S2a).

The isolated proteins from the brush samples were examined by SDS-PAGE (figure S2c). After the freeze-drying, proteins were little isolated from the CPB samples. Thus, we added $500 \mu \mathrm{l}$ of PBS into the collection tubes used for the CPB samples and subjected the solutions to the SDS-PAGE and LC-MS/MS analysis. The bare-SiP showed the complex band pattern similar to the FBS. 
Although the intensity of the bands decreased on the SDPBs, different patterns were seen on the gel. On the other hand, the patterns were little observed on all the CPBs. Contrary to the QCM result, the PHEMA-CPB $(S)$ did not show any protein bands. This was probably because the sensitivity of SDS-PAGE (silver staining) was not high enough to detect the proteins on the PHEMA-CPB $(\mathrm{S})$. With the change in the protein bands of the SDPBs, we expected that different types of proteins would adsorb on the SDPBs.

The isolated proteins were digested by trypsin and subjected to the LC-MS/MS and MASCOT analysis. All the identified proteins (with a score for a match in peptide >27) are listed in supplementary information (table S2). From the UniProt accession number (AC) for each protein (table S2), we classified the proteins into seven functional groups [31]. 106 proteins were identified on the bare SiP. All the SDPBs have some proteins, 31, 41, and 10 proteins for PHEMA, PHEA, and PPEGMA, respectively. On the other hand, none were identified on all the CPBs. The results were in general agreement with the results on QCM analysis and the HUVEC adhesion test with the exception of the PHEMA-CPB(S). It is likely that the amount of protein adsorbed on the PHEMA-CPB $(S)$ was too small to be detected by LC-MS/MS. The total numbers of identified proteins on the SDPBs were much fewer than that on the bare SiP. Additionally, the types of the adsorbed proteins were different on the SDPBs of all the three polymers: For example, serum albumin, a major component in FBS, was not observed on the PPEGMA-SDPB. Cell adhesion proteins were not detected on the PHEMA and PPEGMA-SDPBs.

The reason for the differences in the types of identified proteins on the SDPBs is unclear, but it may be due to surface charge, surface coverage, water content (water structure at surface) or chain mobility resulting from the different chemical compositions of SDPBs.

\section{Conclusion}

We comprehensively studied protein adsorption and cell adhesion on the CPBs of 
PHEMA, PHEA and PPEGMA from the view point of the size exclusion effect attributed to the CPBs. By varying protein sizes $\left(2 R_{\mathrm{g}}\right)$ ranging from 0.5 to $14 \mathrm{~nm}, \mathrm{QCM}$ analysis confirmed that the unique size exclusion effect of CPBs, and thereby protein repellency was observed in all the swollen CPBs. In addition to the protein repellency, the CPBs well suppressed HUVEC adhesions compared with the corresponding SDPBs. The SDS-PAGE and the LC-MS/MS analysis showed that significant levels of FBS proteins adsorbed on the SDPBs, but almost nothing was seen on the CPBs. Interestingly, the number and the type of the identified proteins on the SDPBs depend on the type of polymer used in the brushes. It is postulated that this difference was due to chain mobility, surface charge (coverage), water content or the chemical composition at the outermost surface of the SDPBs. In summary, the swollen CPB structure on a surface would be one of the essential factors for preventing protein adsorption and cell adhesion.

\section{Acknowledgements.}

This research was supported by DSM, The Netherlands, and partially supported by JST-CREST and Nano-Integration Foundry (NIMS) in "Nanotechnology Platform Project" operated by MEXT, Japan. CY thanks Mrs. Fumi Wakui for help with SDS-PAGE experiments.

\section{References}

[1] E. P. K. Currie, W. Norde, M. A. Cohen Stuart, Adv. Colloid Interface Sci. 100-102 (2003) 205.

[2] S. Edmondson, V.L. Osborne, W. T. S. Huck, ChemSoc Rev. 33 (2004) 14.

[3] Y. Tsujii, K. Ohno, S. Yamamoto, A. Goto, T. Fukuda, Adv. Polym. Sci. 197 (2006), 1.

[4] R. Barbey, L. Lavanant, D. Paripovic, N. Schuwer, C. Sugnaux, S Tugulu, H. Klok, A. Chem. Rev. 109 (2009) 5437.

[5] S. Yamamoto, M. Ejaz, Y. Tsujii, M. Matsumoto, T. Fukuda, Macromolecules 33 (2000) 5602.

[6] S. Yamamoto, M. Ejaz, Y. Tsujii, T. Fukuda, Macromolecules 33 (2000), 5608. 
[7] Y. Tsujii, T. K. Okayasu, A. Nomura, K. Ohno, T. Fukuda, J. Phys: Conf. Ser. no. 012031 (2009) 184.

[8] A. Nomura, K. Okayasu, K. Ohno, T. Fukuda, Y. Tsujii, Macromolecules 44 (2011), 5013.

[9] H. He, Y. Tsujii, T. Fukuda, K. Nakanishi, N. Ishizuka, H. Minakuchi, Polym Prepr Jpn (Soc. Polym. Sci. Jpn.) 52 (2003) 2961.

[10] C. Yoshikawa, A. Goto, Y. Tsujii, T. Fukuda, K. Yamamoto, T. Kimura, A. Kishida, Macromolecules 39 (2006) 2284.

[11] C. Yoshikawa, A. Goto, N. Ishizuka, K. Nakanishi, Y. Tsujii, T. Fukuda, J. Polym. Sci. Part A: Polym. Chem. 45 (2007) 4795.

[12] C. Yoshikawa, S. Hattori, T. Honda, C. Huang, H. Kobayashi, Materials Letters 83 (2012) 140.

[13] C. Yoshikawa, Y. Hashimoto, S. Hattori, T. Honda, K. Zhang, D. Terada, A. Kishida, Y. Tsujii, H. Kobayashi. Chem. Letters 39 (2010) 142.

[14] K. Ohno, T. Morinaga, S. Takeno, Y. Tsujii, T. Fukuda, Macromolecules 39 (2006) 1245.

[15] A. Nomura, K. Okayasu, K. Ohno, T. Fukuda, Y. Tsujii,.Macromolecules 44 (2011) 5013.

[16] U. Asolphi, W. -M Kulicke, Polymer 38 (1997) 1513.

[17] J. H. -Y. Liy, D. A. Brant; S. Kitamura, K. Kajiwara, M. Mimura, Macromoelcules 32 (1999) 8611.

[18] C-G. Golander, E. Kiss, J. Colloid Int. Sci. 121 (1988) 240.

[19] M. Malmstern, Colloids Surf. B: Biointerf. 3 (1995) 297.

[20] A. Dolatshahi-Pirouz, T. Jensen, M. Foss, J. Chevallier, F. Besenbacher, Langmuir 25 (2009) 2971.

[21] J. S. Sharp, J. A. Forrest, R. A. L. Jones, Biochemistry 41 (2002) 15810.

[22] A. Baszkin, D. J. Lyman, J. Bio. Mater. Res. 14 (1980) 393.

[23] P. Suttiprasit, V. Krisdhasima, J. Mcguire, J. Colloid. Interface Sci. 154 (1992) 316.

[24] D. C. Carter, X. -M. He, Science 249 (1990) 302. 
[25] F. Hook, M. Rodahl, P. Brzezinski, B. Kasemo, Langmuir 14 (1998) 729.

[26] Kohn, EC. Et al: Proc. Natl. Acad. Sci.USA, 92: 1307-1311, 1995

[27] R. Auerbach,R. Lewis, B. Shinners, L. Kucai, N. Akhtar, Clin. Chem. 49 (2003) 32.

[28] G. Taraboletti, R. Giavazzi, E. J. C. 40 (2004) 881.

[29] Jaffe, E.A. R. L. Nachman,C. G. Becker, C. R. Minick, J. Clin. Invest. 52 (1973) 2745.

[30] K. Ohno, T. Morinaga, S. Takeno, Y. Tsujii, T. Fukuda, Macromolecules 40 (2007) 9143.

[31] B. F. L. Lai, A. L. Creagh, J. Janzen, C. A. Haynes, D.E. Brooks, J. N. Kizhakkedathu, Biomaterials 31 (2010) 6710.

Captions

Table 1. Characteristics of studied brush samples.

Table 2. Absolute and pullulan-calibrated molecular weights, $2 R_{\mathrm{g}}$, crystallographic dimension and amount of adsorption on $\mathrm{SiO}_{2}$ for studied proteins.

Table 3. The number of identified proteins on the SDPBs of PHEMA, PHEA, PPEGMA, and the bare SiP (by MASCOT analysis). The identified proteins were categorized into seven protein types. 
Figure 1. Amount of irreversibly adsorbed proteins onto (a) PHEMA brushes, (b) PHEA brushes, and (c) PPEGMA brushes, soaked for $1 \mathrm{~h}$ at $25{ }^{\circ} \mathrm{C}$. The protein concentration was $1.0 \mathrm{~g} / \mathrm{L}$ in all cases. The amounts were normalized with the value on the $\mathrm{SiO}_{2}$ surface.

Figure 2. Amount of adherent HUVECs on the brushes for (a) 1 day, (b) 4 day, and (c) 7days. $[\text { HUVEC }]_{0}=10000$ cells $/ \mathrm{cm}^{2}$ for 1 and 4 days, and 2500 cells $/ \mathrm{cm}^{2}$ for 7 days. The number of adherent cells was normalized with the value on that of seeded cells.

Figure 3. Amount of adsorbed proteins from FBS on the surfaces. 
PHEMA
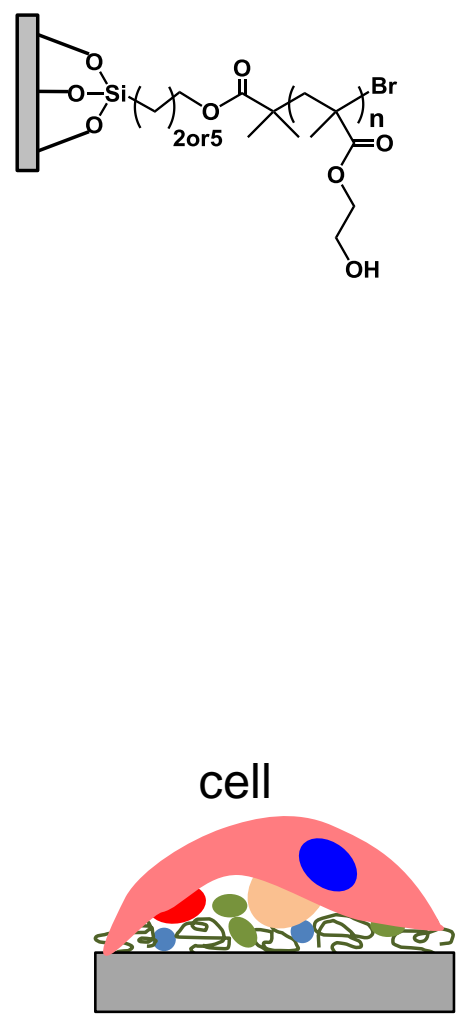

Semi-diluted polymer brush
PHEA

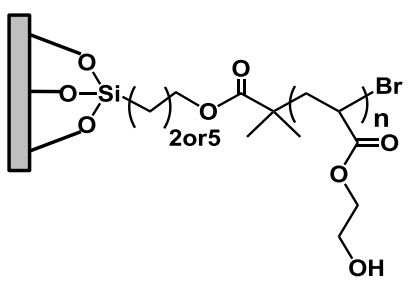

protein

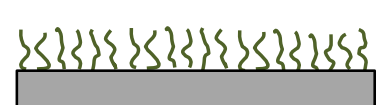
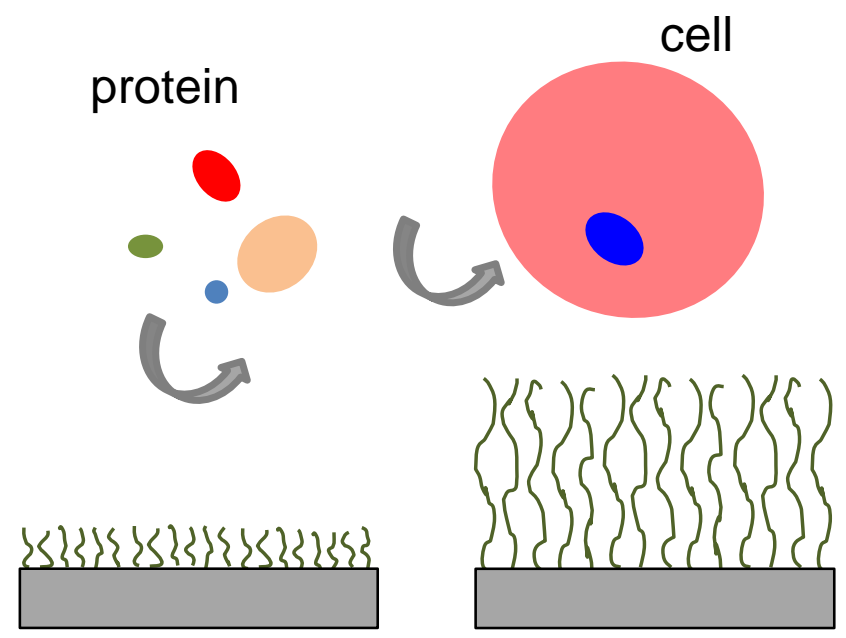

Concentrated polymer brushes (with different chain lengths) 
Figure 1

(1) PHEMA

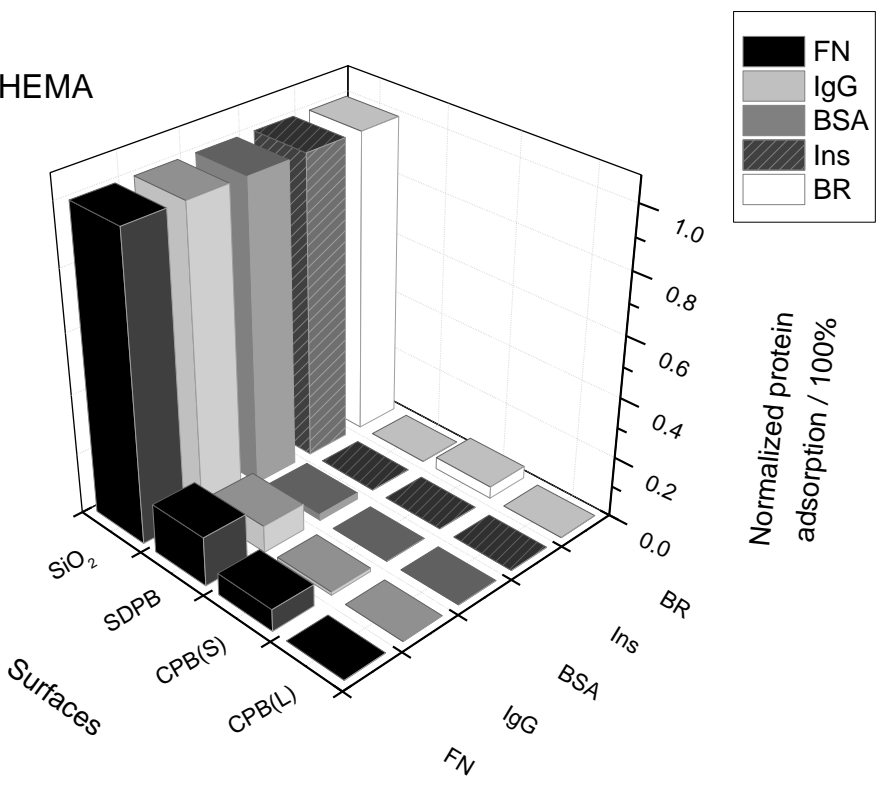

(2) PHEA

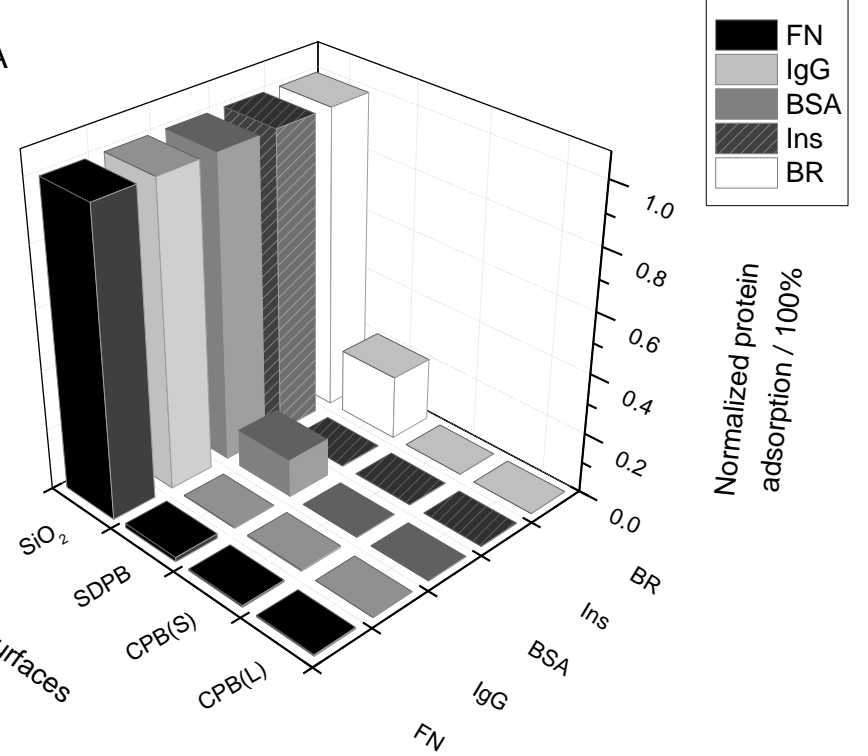

(3) PPEGMA

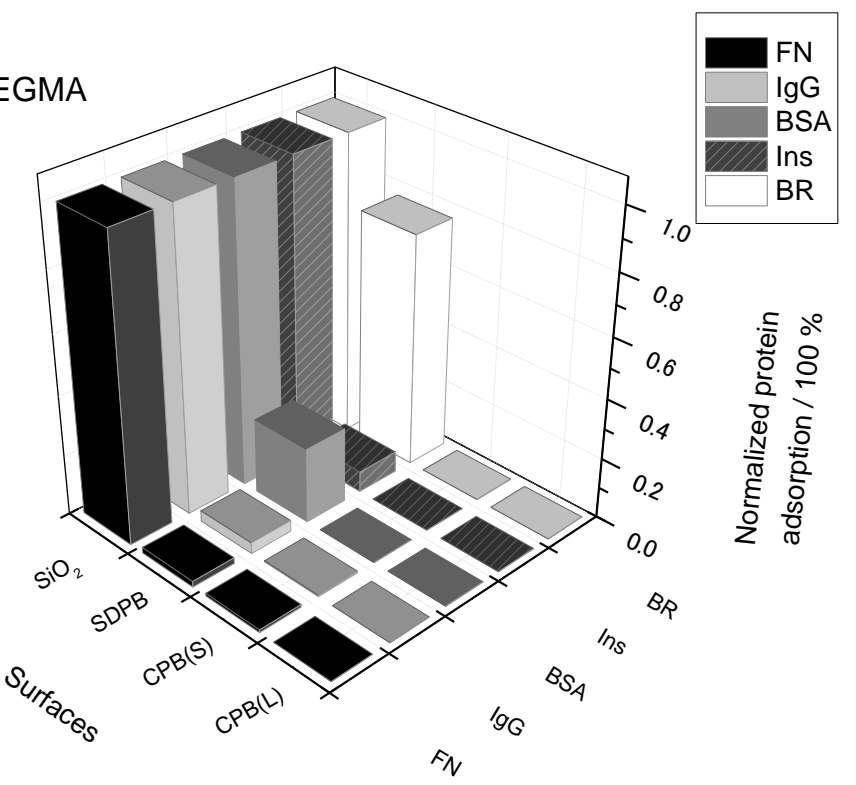


Figure 2

(a) 1 day

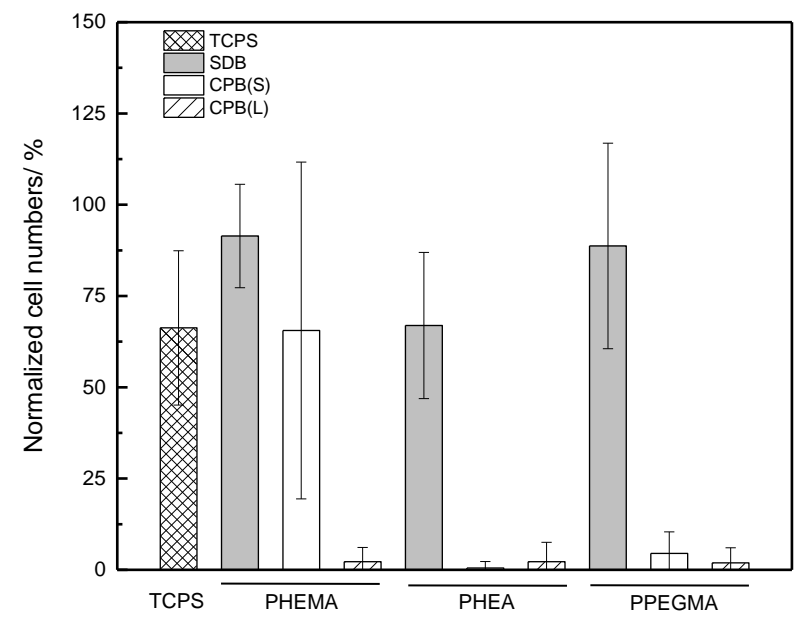

(b) 4 days

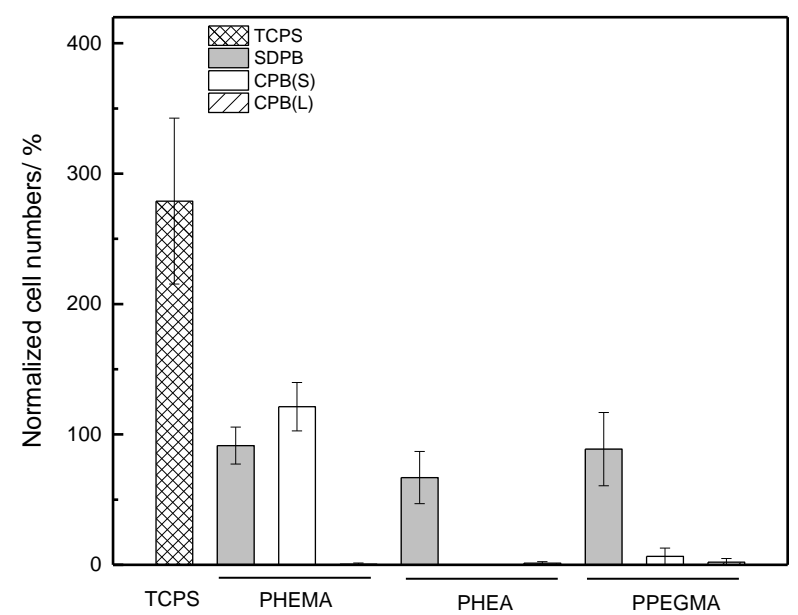

(c) 7 days

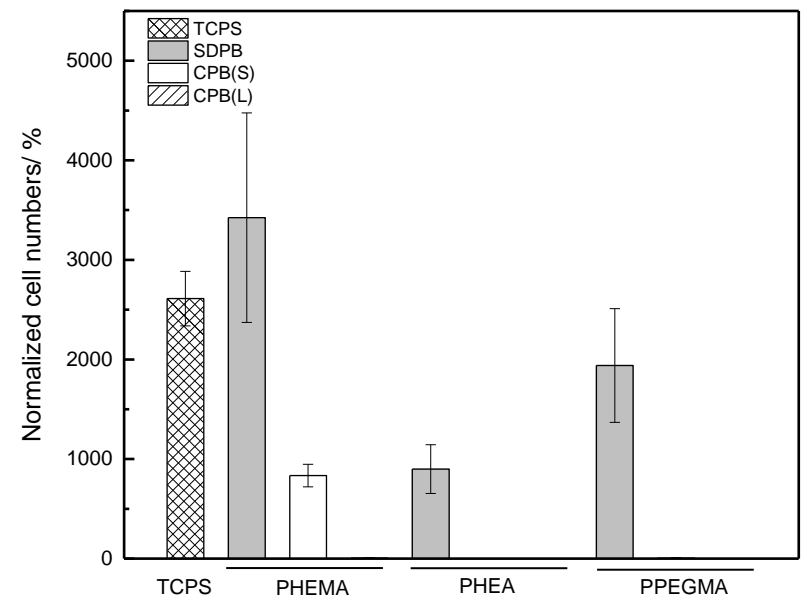


Figure 3

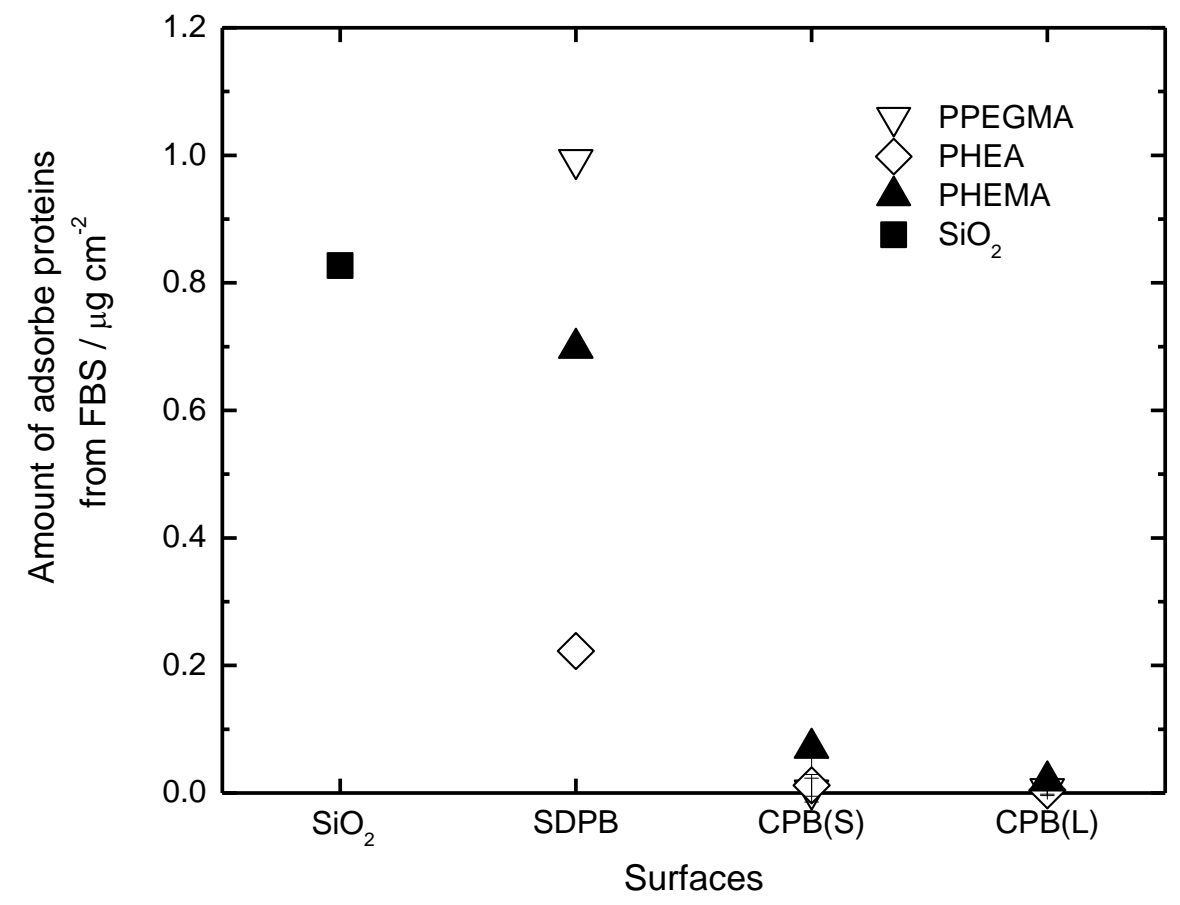


Table 1.

\begin{tabular}{|c|c|c|c|c|c|c|c|c|c|}
\hline Polymers ${ }^{a}$ & & $M_{\mathrm{n}}^{\mathrm{b}}$ & $M_{\mathrm{w}} / M_{\mathrm{n}}^{\mathrm{b}}$ & $M_{\mathrm{n}, \mathrm{conv}}{ }^{c}$ & $\begin{array}{l}L^{d} \\
/ \mathrm{nm}\end{array}$ & $\begin{array}{l}\sigma^{e} \\
\text { / chain } \mathrm{nm}^{-2}\end{array}$ & $\begin{array}{l}d\left(=\sigma^{-0.5}\right) \\
/ \mathrm{nm}\end{array}$ & $\sigma^{* f}$ & $\theta$ \\
\hline \multirow{3}{*}{ PHEMA } & SDPB & 19600 & 1.22 & 18400 & 2.7 & 0.10 & 3 & 0.075 & 30 \\
\hline & $\overline{\mathrm{CPB}(\mathrm{S})}$ & 7800 & 1.23 & 2600 & 2.5 & 0.60 & 1 & 0.45 & -- \\
\hline & $\mathrm{CPB}(\mathrm{L})$ & 13400 & 1.25 & 15300 & 12.4 & 0.56 & 1 & 0.42 & 29 \\
\hline \multirow{3}{*}{ PHEA } & SDPB & 4600 & 1.26 & 6200 & 1.7 & 0.16 & 3 & 0.12 & 28 \\
\hline & $\mathrm{CPB}(\mathrm{S})$ & 1200 & 1.18 & 1300 & 2.3 & 1.06 & 1 & 0.82 & 29 \\
\hline & $\mathrm{CPB}(\mathrm{L})$ & 5700 & 1.20 & 8260 & 10.9 & 0.72 & 1 & 0.56 & 26 \\
\hline \multirow{3}{*}{ PPEGMA } & SDPB & 42200 & 1.14 & 30000 & 1.4 & 0.03 & 6 & 0.09 & 35 \\
\hline & $\mathrm{CPB}(\mathrm{S})$ & 13700 & 1.12 & 7000 & 2.3 & 0.19 & 2 & 0.59 & 35 \\
\hline & $\mathrm{CPB}(\mathrm{L})$ & 40500 & 1.18 & 47000 & 12.9 & 0.17 & 2 & $=-\overline{-}$ & 30 \\
\hline
\end{tabular}

${ }^{2}$ Characteristics of brushes were almost identical on silicon wafers and QCM chips, and typical values on silicon wafers are listed. ${ }^{b}$ EstimatedbyPEG-calibrated GPC for PHEMA and PHEA, and by PMMA-calibrated GPC for PPEGMA. ${ }^{c}$ Calculated according to $M_{n, \text { conv }}=[$ [monomer] $/$ /free initiator] $\times \mathrm{MW} \times$ Converstion. ${ }^{d}$ The error is within $10 \%$. ${ }^{e}$ Calculated with $L$ and $M_{\mathrm{n}, \text { conv }}$ according to eq $2 .{ }^{f} \sigma^{\star}$ is dimensionless graft density defined as $\sigma^{\star}=$ $\mathrm{a}^{2} \sigma$, where $\mathrm{a}^{2}$ is the cross-sectional area per monomer unit. 
Table 2.

\begin{tabular}{llllll}
\hline Protein & $M$ & $M_{\text {pul }}$ & $2 R_{\mathrm{g}} / \mathrm{nm}^{\mathrm{a}}$ & $\begin{array}{l}\text { Crystallographic } \\
\text { dimension } / \mathrm{nm}\end{array}$ & $\begin{array}{l}\text { Amount of adsorption } \\
\text { on } \mathrm{SiO}_{2} / \mathrm{\mu g} \mathrm{cm}^{-2}\end{array}$ \\
\hline Bradykinin (BR) & 1100 & 90 & 0.5 & - & 0.021 \\
Insulin (Ins) & 5800 & 1300 & 2 & $2.5 \times 3.5$ & 0.063 \\
Albumin (BSA) & 67000 & 22100 & 10 & $14 \times 3.8 \times 3.8$ & 0.15 \\
Immuno globulin (IgG) & 150000 & 33300 & 13 & $23.5 \times 4.4 \times 4.4$ & 1.0 \\
Fibronectin (FN) & 440000 & 35400 & 14 & $13.8 \times 1.44$ & 1.4 \\
\hline${ }^{2}$ Calculated (see text). & & & & &
\end{tabular}

${ }^{a}$ Calculated (see text). 
Table 3.

\begin{tabular}{lllll}
\hline Protein type & Bare SiP & PHEMA-SDPB & PHEA-SDPB & PPEGMA-SDPB \\
\hline Apolipoproteins & 5 & 2 & 3 & 0 \\
Coagulation-related proteins & 21 & 3 & 9 & 1 \\
Inflammation-related proteins & 8 & 1 & 1 & 0 \\
Cell adhesion proteins & 2 & 0 & 1 & 0 \\
Actin/actin-binding proteins & 5 & 2 & 2 & 1 \\
Cell surface-related proteins & 30 & 8 & 5 & 4 \\
Other proteins & 35 & 15 & 20 & 4 \\
\hline Total number of proteins & 106 & 31 & 41 & 10 \\
\hline
\end{tabular}

